\title{
La esperanza y los mártires
}

El Salvador necesita esperanza y la pregunta es de dónde sacarla. Lo primero es claro, porque para trabajar en provecho propio basta el egoísmo, pero para trabajar por los demás, y en concreto por las mayorías pobres, se necesita el ánimo que sólo la esperanza genera. Con ella podremos intentar erradicar los seculares y graves males que siguen configurando el país - la indiferencia y aun la crueldad con respecto a la vida de las mayorías sobre todo-, y podremos intentar avanzar, aunque sea un poco, por los caminos que ya se han abierto.

No se puede ignorar que algo han cambiado las cosas, lo cual permite esperar que puedan seguir cambiando. Pero tampoco se debe ignorar que las posiblidades de la nueva situación son todavía endebles y ambiguas, abiertas a un futuro de justicia, pero abiertas también a mantener un pasado de cruel injusticia. Algo hay ya, pues, que anima a la esperanza, pero no se debe pasar por alto que también hay mucho que conduce al desencanto.

La conclusión es que se necesita esperanza para empujar lo positivo y erradicar lo negativo. $Y$ si nos preguntamos de dónde sacar la esperanza necesaria, la respuesta son los mártires. En El Salvador, la esperanza proviene de los mártires. No sólo de ellos, pero sí muy principalmente de ellos.

Esto no lo digo a modo de panegírico en días de aniversario, sino con convicción personal y aun teórica. Las expectativas sobre el medro personal provienen del egocentrismo y de los estímulos sociales que nos ofrece la mal llamada civilización actual. Pero la esperanza es otra cosa. La generan aquellos seres humanos que, a pesar de todo y en contra de todos los obstáculos de nuestra civilización egoísta, nos ofrecen generosidad, decisión de dar vida a los pobres, aunque en ello les vaya a ellos la propia vida. En una palabra, la esperanza procede del amor. Y si la expresión parece inadecuada por meliflua, piénsese qué otra realidad produce esperanza.

El silencio que se ha cernido sobre mártires y caídos. Quiero comenzar diciendo que esperanza y mártires son cosas bien reales, y si lo recalco es porque algo muy significativo y sumamente peligroso está ocurriendo con ambas cosas. Se trata del intento de privarlas de realidad, como si los mártires, por ser cosa del pasado, y la esperanza, por ser cosa del espíritu, no fuesen ya cosas reales. Por ello, mi primera reflexión consistirá en analizar cómo y por qué se está dando el olvido de mártires y caídos.

Por lo que toca a los caídos, poco se mencionan ya sus nombres y mucho menos se les presenta como ejemplo de salvadoreños ejemplares. Al menos en público, es notorio el silencio que se ha cernido sobre ellos en el lenguaje oficial, en el de instituciones conjuntas a las que pertenecen las dos partes que firmaron los acuerdos e incluso en el de los grupos de izquierda. Por lo que toca a los mártires, tampoco se han excedido jerarcas y sacerdotes en recordarlos, y el simple fiel comienza a sentir ese silencio y acaba por introyectarlo. La conferencia episcopal no ha escrito en quince años un documento serio sobre los miles de salvadoreños asesinados y caídos, pero ni siquiera sobre los 
miles de cristianos a quienes les quitaron la vida, como a Jesús, por haber defendido a los pobres y denunciado a los poderosos.

Este nos parece ser el hecho fundamental. En el ámbito oficial, los gobernantes, los jefes militares, los políticos, la embajada de Estados Unidos, ONUSAL... no mencionan ya a mártires y caídos. Y tampoco los mencionan los jerarcas eclesiásticos, con la excepción de Monseñor Rivera - y su empeño en la canonización del mártir Monseñor Romero-, más el cariño y la admiración que mantienen las comunidades $\mathrm{e}$ instituciones como la UCA.

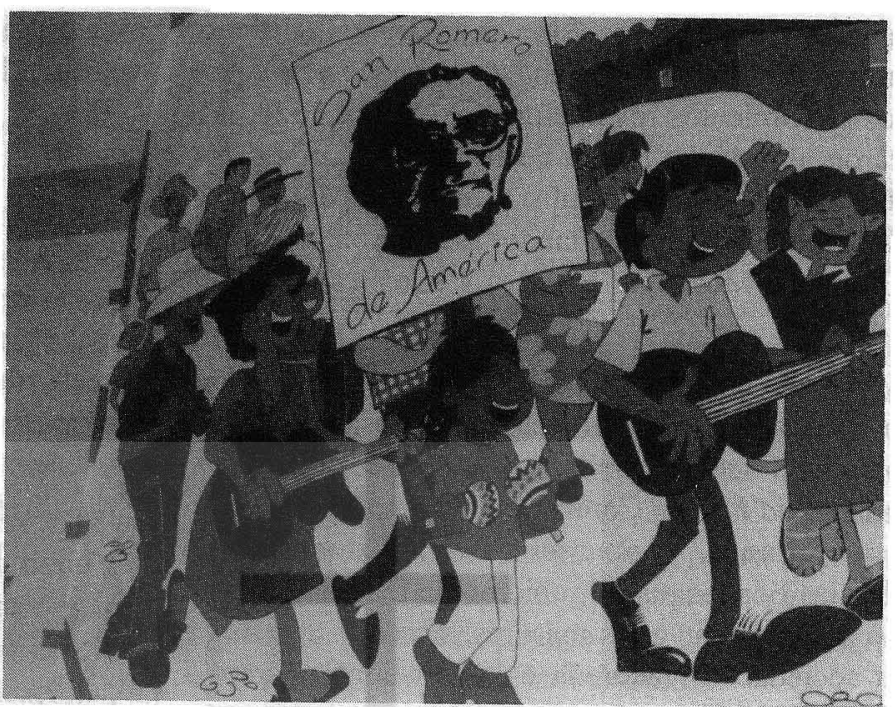

Para mantener este silencio se pueden aducir diversas razones $\longrightarrow$ dar por supuesto que ya no hay que justificarlo. Y esto hay que analizarlo detalladamente por lo que está en juego.

La razón fundamental que se aduce consiste en repetir que las cosas han cambiado, y de ahí la campaña para olvidar el pasado y el que se escuchen simplismos como el que "la historia es para los historiadores". Esa "irrealidad" del pasado la quieren extender también a los mártires y a los caídos, pues reconocerlos, añaden, traería más males que bienes en el momento actual: traumas sociales, intolerancia y agresividad, cosas todas que deben desaparecer del nuevo El Salvador. La nueva democracia necesita, más bien, de un ambiente psico-social distinto y aun contrario al que produce el recuerdo de los mártires: pluralismo, tolerancia, diálogo... En resumen, recordar a los mártires sería un obstáculo más que una ayuda para hacer avanzar el país sobre todo por lo que toca a la reconciliación, cosa sumamente importante y necesaria, pero que es tratada con ligereza - como si ésta hubiese realmente comenzado- y con poca precisión lógica confundiendo pactos políticos entre las partes con con-vivencia fraternal entre los salvadoreños.

Tratando de buscar lógica a estas bizartas afirmaciones, se puede conceder que recordar la negrura de los asesinatos pudiera suscitar todavía reacciones descontroladas, aunque es evidente que

olvidarlos simple y llanamente sería peor, pues facilitaría su repetición. Pero lo que es inaceptable y tiene muy poca lógica es pensar que recordar la generosidad y el amor de los mártires no sólo no tiene nada positivo que ofrecer al país, sino que difucultaría el proceso de paz. Quien esto piense y afirme es que no tiene interés en que el proceso salvadoreño sea realmente humano y humanizante, sino que sólo está interesado en cómo salir bien parado de los problemas políticos inmediatos.

Muchos nos ofrecen, pues, el silencio como lo más oportuno en estos momentos. Pero, además, sus ideólogos - los del pragmatismo, los de un mal entendido realismo o los de la postmodernidad-, lo teorizan como un bien y como una manera para neutralizar el potencial agresivo de todo pensamiento liberador y revolucionario, incluido el religioso (y la verdad es que el fundamentalismo islámico ofrece un buen argumento para ello), con lo cual lo mejor que podría hacer ahora tal pensamiento liberador es guardar silencio sobre los mártires para erradicar las raíces de la agresividad social. Aunque no con estas palabras, lo que estarían diciendo es que los movimientos de liberación y la misma religión están muy necesitados de pensamiento democrático para atemperarse.

Otros, los del lado eclesial conservador, se alegran que se cierna el silencio sobre los mártires por la sencilla razón de que para ellos nunca ha 
habido tales mártires, sino, a lo sumo, cristianos ingenuos de buena voluntad que cooperaron con los movimientos revolucionarios. "Ellos se lo buscaron al meterse donde no les tocaba", como han dicho altos jerarcas, dentro y fuera del país, incluido algún cardenal, cuando asesinaron a Rutilio Grande, a Monseñor Romero y a los jesuitas de la UCA.

Otros, por último, los responsables de las aberraciones y de los crímenes inconfesables, cuyos nombres, hechos públicos o no, los conoce la Comisión ad hoc, la Comisión de la verdad y el Grupo conjunto, y aparecen en los documentos desclasificados por el gobierno de Estados Unidos, no sólo ignoran a los mártires, sino que desafían a la sociedad salvadoreña e intemacional, como si de nada tuvieran que arrepentirse $y$, ciertamente, no de haber asesinado a gente buena, generosa, amorosa, pacífica e indefensa.

La conclusión es que, en una nueva situación y en camino hacia la democracia, nos quieren imponer como lo mejor el olvido de todo lo que recuerde antagonismos, conflictos y agresividad. Pero no debiera ser así.

Cierto es que la tolerancia es buena, pero también es cierto que de ella a la indiferencia no hay más que un paso. $Y$ así, las tolerantes democracias del norte del planeta pueden contemplar sin pestañear cómo se mueren de hambre anualmente de veinte a treinta millones de seres humanos - lo cual sigue ocurriendo también en El Salvador-y pueden contemporizar con lo que ocurre en Ruanda, Haití, Chad o Nicaragua. Cierto es que la democracia puede ser buena para atemperar la agresividad de los pensamientos revolucionarios y religiosos, pero es también cierto que de ello al adormecimiento no hay más que un paso, y a como vamos en el país, cada vez se hace más necesario el potencial profético utópico de lo religioso que espolee a las democracias sin entrañas. Cierto es que debe fomentarse el pluralismo, la diversidad en formas de pensar y de creer, pero también es cierto que no puede reducirse a simple pluralismo la diferencia fundamental entre quienes dan la vida por supuesto y quienes lo que no dan por supuesto es precisamente la vida. Los ricos Epulones y los pobres Lázaros de nuestros días no son candidatos al pluralismo, sino a la conversión unos y a la muerte otros.

Los pragmatistas de hoy y sus teóricos deben preguntarse en serio - y sin mantener el dogmatismo de antaño, según el cual sólo ellos estarían en posesión de la razón- si el olvido de los mártires y de los caídos está humanizando o deshumanizando al país. En concreto, si ese olvido está generando esperanza o desencanto. Pero para poder responder a esa pregunta veamos quiénes son los mártires y cuál es su función en la sociedad.

La verdad es posible. Muchas veces he preguntado a gente sencilla quién fue Monseñor Romero para ellos, y la respuesta en lo fundamental ha sido unánime: "Monseñor Romero dijo la verdad, nos defendió a nosotros de pobres y por eso lo mataron". De esta forma están diciendo que mártir es aquel a quien le quitan la vida, pero por razones bien precisas: por decir la verdad y por defender al pobre. Y de esta forma, aun sin saberlo, la gente sencilla está unificando las dos tradiciones cristianas acerca del martirio. Una, más en la línea de la verdad, según la cual mártir es el que da con su vida testimonio de la verdad. Y la otra, más en la línea del amor, según la cual mártir es el que entrega la vida por amor a los hermanos. Por lo que toca a nuestro tema, lo fundamental consiste en que, tanto ayer como hoy, en los tiempos de persecución del Nuevo Testamento como en los tiempos de represión y persecución de estos años, los mártires generan y mantienen esperanza.

Así fue y así es en la realidad. En El Salvador, desde hace muchos años y ciertamente desde los setenta, se ha establecido un proceso a la verdad, y en ese proceso ha habido testigos verdaderos y testigos falsos. Falsos testigos han sido los gobernantes y los generales de la Fuerza Armada quienes han mentido en discursos oficiales, varios de los medios de comunicación que, además, han propalado la mentira de los poderosos del capital, los administradores de justicia que no han investigado crímenes ni juzgado a sus responsables -y tristemente, tampoco ha faltado algún jerarca eclesial. En el país se ha manoseado y manipulado la verdad hasta el extremo de intentar hacer pasar a los pobres por culpables del los males, mientras que los poderosos han sido presentados como la 
fuente de todos los bienes. Se presentó a Monseñor Romero como el malo y bueno fue quien ordenó matarlo — de lo cual todavía no se han retractado ni el actual presidente ni su antecesor.

¿Y hoy? Hay que reconocer que ha habido serios y loables intentos para mejorar la situación, como el de la Comisión de la verdad, pero todavía no existe — ni de lejos - una clara voluntad de verdad. A la verdad se le imponen límites cuando resulta dura y escandalosa o se decide - argumento al que se apela ahora con excesiva frecuenciaque mejor es no insistir en la verdad, pues de esa forma se entorpecería la marcha del proceso.

Se está dando, como cosa normal, un encubrimiento de la realidad que, no por menos burdo y más sutil, deja de serlo. Con educación y corrección, con gestos pulidos y elegantes, con voces pausadas, se quiere comunicar la normalidad de la situación y su correcta dirección hacia el futuro. Se maneja de tal manera la existencia de los secuestros, los asesinatos, la liberación de los narcotraficantes, la corrupción inocultable, los motines y asesinatos en las cárceles, las muertes en los basureros, como el de Santa Eduvigis, y el aumento del número de pobres que parece que ya nada puede doler.

Y más allá de los encubrimientos y las mentiras concretas en que se expresa la falta de voluntad de verdad, el país no está ofreciendo símbolos de querer basarse en la verdad, sino, con frecuencia, todo lo contrario. Que entre los garantes de la paz se nombre a civiles y militares quienes han sido reponsables de horrendos crímenes en el pasado o de su encubrimiento, sin que hasta el día de hoy hayan pedido perdón y, peor aún, sin que se hayan dejado perdonar, rechazando el perdón que se les ha ofrecido, es hundir más hondamente en tierra las raíces de la mentira y del encubrimiento en El Salvador. Y a pesar de los intentos para explicar el hecho, nadie nos ha convencido que puedan ser buenos garantes de la paz quienes han asesinado a quienes trabajaron por la paz.

¿Quién nos ha liberado y nos puede liberar de tanta mentira, tan institucionalizada, por cierto, como la injusticia y la violencia? ¿Quién puede redimir el encubrimiento y revertir así esa corrien- te profunda que mueve la historia salvadoreña y que la deshumaniza?

El nuevo cauce por el que se mueve el país, algo puede ayudar, pero hay que estar claros que no es suficiente ni que, por la naturaleza del asunto, eso se logra fundamentalmente con decretos y pactos políticos. Sólo lo pueden lograr los que son testigos de la verdad y los que están dispuestos a dar testimonio de ella hasta el final con su propia vida. Que ocurra esto último se debe a que el maligno es mentiroso y a que las tinieblas odian la luz, como dice el evangelio de Juan. $Y$ también los poderosos y opresores de hoy pagan bien la mentira y odian la verdad. Pero esta reacción de la mentira esclarece quiénes son los mártires y cuán beneficiosos y necesarios son.

Los mártires, entonces, tienen la función, difícil y arriesgada - y por ello tan rehuída- de defender la verdad en la sociedad. Y son los que generan esperanza porque nos dicen que la verdad es posible. $\mathrm{Y}$ recordemos que la verdad siempre está mucho más en favor de los pobres que de sus opresores, y que, con frecuencia, la verdad es lo único que los pobres tienen en su favor.

El amor es posible. Los mártires en nuestro país no han sido masoquistas, ni fanáticos religiosos, ansiosos de derramar sangre, ni la ajena ni la propia. Han sido, más bien, gente de compasión y de misericordia. Entre nosotros, el martirio ha sido ante todo expresión de un gran amor a los pobres, los que sufren pobreza, opresión, represión y muerte. Los mártires, y esto hay que recalcarlo, no han dado su vida por conseguir nada para ellos, ni poder ni riqueza, sino para que las mayorías tengan vida. Por esa razón nos remiten a la realidad de la pobreza, que sigue siendo muy real, que debe ser denunciada por la profecía y combatida por la utopía del amor. Y la pobreza, a su vez, nos remite a los mártires, pues quien lucha en favor del pobre es perseguido y destrozado por la riqueza.

Por qué esto sea así, es el gran enigma de la historia, el mysterium iniquitatis, al menos para aquellos que todavía se preguntan por estas cosas sin deslizarse en la trivialidad del "vivamos lo mejor posible". Pero es también la gran pregunta 
existencial: si seguir defendiendo al pobre o no, si luchar contra acaparadores y verdugos sólo "desde fuera", con las armas de la palabra, del poder social, político o diplomático, o luchar también "desde dentro", cargando con el pecado de este mundo.

No sé si esta idea de cargar con el peso del pecado es importante en otras corrientes de pensamiento - ciertamente no creo que lo sea en el de la postmodernidad-, pero le es esencial a la fe cristiana. Y por cierto, así pensaba Ellacuría, tan invocado hoy, inesperadamente, en apoyo de todo tipo de pragmatismos inmediatistas e interesados, y tan silenciado en su exigencia ética de denuncia y en su invitación a propuestas utópicas. Pues bien, para erradicar el mal, decía, hay que combatirlo ética y humanamente con todas las armas posibles, pero hay que estar también dispuestos a cargar con ese mal hasta el extremo de que anonade a quien carga con él. Según esto, mártir es el que carga con la realidad y se deja anonadar por ella, aunque no por haber buscado el propio provecho, sino por amor a las víctimas.

Quizás algunos sesudos analistas podrán aceptar la lógica de la argumentación: si hay martirio es que ha habido amor - justicia, misericordia, compasión-, pero podrán preguntar para qué queremos amor si de configurar la sociedad se trata, y lo hacen quizás desde la frialdad de una ciencia neutral y objetiva.

Pues bien, desde una perspectiva cristiana, el amor es necesario para llegar a ser simplemente humano. A la pregunta de quién es el ser humano cabal la Escritura responde que lo es aquel a quien se le remueven las entrañas ante el sufrimiento de las víctimas y, por esa sola razón, las defiende y las sana. Y para el creyente, recordemos unas palabras muy citadas hace años: "Practicar la justicia, eso es conocerme", dice Yahvé; aunque estas palabras ahora están corriendo la suerte de otras muchas de aquel tiempo: "la Iglesia de los pobres", "la santidad política", "fe y justicia".

$Y$ digamos de pasada que la lectura de la Escritura no debiera inducimos a engaño como si sus textos nos introdujesen en una realidad de tipo angélico y celestial. Por ello, si se me permite el comentario, es peligroso hablar rutinariamente de la sagrada Escritura, y no estaría de más hablar de vez en cuando de ella como de la humana Escritura.

Pero, volviendo al tema, podemos hablar también de la necesidad del amor (de la justicia, la compasión, la misericordia) desde una perspectiva política - aunque hace falta una buena dosis de utopía para siquiera abordar el tema. Todo el mundo, con buenas razones o por intereses particulares, proclama ahora cuán buena y necesaria es la democracia. Pero no queda nada claro en qué consiste la bondad de ésta ni qué fundamentos son necesarios para que llegue a ser realidad.

La tradición occidental ha formulado esos fundamentos como "libertad, igualdad y fraternidad". En la realidad, sin embargo, es cierto que se insiste en la "libertad", la libertad económica, sobre todo para los pocos, que casi siempre es usada en provecho propio y contra las mayorías. Pero sobre lo otro, la igualdad y la fraternidad, no se dice prácticamente nada, ni siquiera en el discurso teórico. Muy poco se dice de la igualdad y nada de la fraternidad. Y así nos va en nuestra democracia, $\sin$ fraternidad $y \sin$ amor.

Lo acabamos de constatar, una vez más, en California, lugar de gran tradición democrática, donde se puso a votación si se les niegan los servicios médicos y educativos o no a cientos de miles de seres humanos, entre ellos niños y ancianos. $Y$ a nivel mundial, la realidad que han generado los países del norte es escandalosa y antidemocrática.

El dominio de los grandes grupos financieros e industriales y la concentración de la riqueza en unos pocos ha sido un fenómeno constante a lo largo de estos 50 años y se ha intensificado en la última década. Así, cuando en 1960, el 20 por ciento de la población más pobre del planeta se repartía el 2.3 por ciento de la renta mundial, este porcentaje ha disminuido al 1.7 por ciento en 1980 y al 1.4 por ciento en 1990 . Mientras tanto, el 20 por ciento de los más ricos pasaba del 70.2 por ciento en 1960 , al 76.3 por ciento en 1980 y al 82.7 por ciento en 1990 (José María Mella Márquez, Universidad Autónoma de Madrid, Vida Nueva, 29 de octu- 
bre, 1994, p. 28).

Entre nosotros lo que vemos es el enriquecimiento rápido de unos pocos y la corrupción. Y el foro de concertación, en el que se buscaba distribuir más humanamente lo que producimos los salvadoreños, es el que más estrepitosamente ha fracasado. Poco importa que los obispos de la capital repitan periódicamente que la pobreza va en aumento. El clamor de los pobres no llega a los oídos de los que tienen como finalidad en su vida seguir enriqueciéndose. No hay un abajamiento de los que viven en abundancia escandalosa a los que viven en escandalosa miseria. Y cuando se apela al rebalse, a que llegará el día en que las migajas de la mesa del rico Epulón llegarán hasta el pobre Lázaro, se hace con el deseo de que así sea para que no tenga que cambiar mucho la situación de los ricos. Los pobres han escuchado esto del "rebalse" $\longrightarrow$ su equivalente- durante años. Y siguen esperando. Los ricos no han dado todavía un paso serio hacia la reconciliación.

¿Quién nos puede liberar de tanto desamor y de tanta injusticia? Muchas cosas son necesarias para conseguir esta liberación, por supuesto. Pero son necesarios ante todo símbolos eficaces que nos comuniquen que se puede vivir de otra manera, con amor a los pobres de este mundo, y que desde ese amor - no desde el propio provecho, el del propio partido o el de la propia Iglesia- se puede revertir la historia.

El maligno es mentiroso, decíamos antes. Añadimos ahora, en la misma tradición de Juan, que es asesino. Por eso, quien ama en verdad tiene que estar dispuesto al martirio. Esta es la tragedia. Pero el martirio a su vez muestra que ha habido un gran amor. El amor es posible, dicen los mártires, y éste mensaje no es desdeñable.

La esperanza que producen los mártires. Para que el país tenga solución se necesita realismo, pragmatismo y compromisos incluso, y sin ello ni se hubiera acabado la guerra ni se hubiesen firmado los acuerdos de paz. Estamos, pues, en un cauce, nuevo hasta cierto punto y con posibilidades, que no se debe ignorar por una tendencia fanatizada hacia la denuncia, pero que tampoco se debe exaltar por voluntarismos interesados $y$ obnubilados. Hay que proseguir, pues lo bueno que permite el nuevo cauce.

Pero el cauce no basta. Se necesita, urgentemente y en grandes dosis, verdad y amor. No son éstos los bienes políticos que parecieran ser ahora los más importantes, y ciertamente, no son los bienes económicos de los que estamos tan urgidos. Pero mal construiremos un nuevo El Salvador sin estos bienes sociales de la verdad y del amor.

Indudablemente, hay que historizarlos, pero historizarlos no significa desvirtuarlos ni manipularlos ni anularlos. Significa que hay que hacer propuestas positivas, pero desde esta perspectiva, propuestas que versen sobre lo que en la sociedad es el ámbito de la verdad: la investigación y la administración de justicia, el uso y la finalidad de los medios, la verificación del discurso oficial e ideológico; y también sobre lo que es el ámbito del amor: la economía para las mayorías, la salud, la educación, los derechos humanos...

Pero además de ser necesarios en sí mismos, la verdad y el amor generan esperanza. Con ella, la vida tiene sentido, y sin ella, sólo queda el desencanto o la huída. Con ella hay ánimo para trabajar por una sociedad justa y veraz, y sin ella sólo queda el egoísmo o la resignación del "sálvese quien pueda". Por ello, aun cuando existe un nuevo cauce, es necesario imbuirlo de espíritu, de esperanza, que anime a trabajar con generosidad y sin egoísmo, con audacia y sin desidia, por los pobres del país.

Terminamos como comenzamos. Verdad y amor es lo que, a raudales, nos han dejado los mártires, y con ellos la esperanza. Dicho en palabras del pronunciamiento de la UCA: "No toda vida es ocasión de esperanza, pero sí lo es la vida de los mártires que, por amor, cargaron sobre sí con el pecado social, siguiendo el ejemplo de Jesús".

Al pueblo salvadoreño lo caracteriza su laboriosidad y su terquedad. También la terquedad de la esperanza. Por eso, la UCA y muchos otros siguen celebrando, tercamente, el recuerdo de los mártires. En ello nos va no sólo el ser agradecidos, sino el ánimo para luchar contra la mentira y la crueldad, y para construir un país humano y fra- 
terno.

Quiero terminar con unas palabras de Ignacio Ellcuría sobre la esperanza, son las mismas palabras con las cuales termina también el pronunciamiento de la UCA, palabras que parecen un desatino, pero que siguen teniendo una gran fuerza. En cualquier caso, todavía nadie nos ha convencido de lo contrario:
Toda esta sangre martirial derramada en $\mathrm{El}$ Salvador y en toda América Latina, lejos de mover al desánimo y a la desesperanza, infunde nuevo espíritu de lucha y pueva esperanza.

Jon Sobrino.

Cátedra de realidad nacional, 14 de noviembre de 1994. 